\title{
Effects of Medium Molecular Weight Heparinyl Phenylalnine on Superoxide Dismutase Activity in Mice
}

\author{
SEIICHI TAKEDA ${ }^{1}$, TAKAO TODA ${ }^{1}$ and KAZUKI NAKAMURA ${ }^{2}$ \\ ${ }^{1}$ Research and Development Center, Fuso Pharmaceutical Industries LTD., Osaka, Japan; \\ ${ }^{2}$ Department of Pharmacology, School of Pharmacy and Pharmaceutical Sciences, \\ Mukogawa Women's University, Hyogo, Japan
}

\begin{abstract}
We investigated the radical scavenging ability of heparin (HE), medium molecular weight heparinyl phenylalanine $(\mathrm{MHF})$ and medium molecular weight heparinyl leucine (MHL) in the blood of mice. The extracellular superoxide dismutase (EC-SOD) activity was measured according to the method by Oyanagui and Sato. As a result, $H E$ significantly increased the EC-SOD activity with a significant prolongation of activated partial thromboplastin time (APTT), while MHF and MHL significantly increased the EC-SOD activity without a prolongation of APTT. Dose-response curve at $20 \mathrm{~min}$ after the injection of each compound indicated a bell-shape. Changes in the plasma EC-SOD activity of mice after the administration of HE, MHF and MHL $(10 \mathrm{mg} / \mathrm{kg} / 10 \mathrm{ml})$ were investigated time-dependently. The plasma EC-SOD activity peaked at 5 min after the administration of all compounds. These results indicated that MHF and MHL show a radical scavenging ability by increasing the EC-SOD activity and MHF may be a candidate for clinical use.
\end{abstract}

In our previous studies, we reported that medium molecular weight heparinyl phenylalanine (MHF) and medium molecular weight heparinyl leucine (MHL) have preventative effects against cultured human umbilical vein endothelial cells (HUV-ECs) damaged by oxygen-free radicals and ischemic paw edema in mice without prolonged activated partial thromboplastin time (APTT). MHF and MHL are superior to heparin (HE) as safe radical scavengers $(1,2)$. However, the mechanism of MHF and MHL as radical

Correspondence to: Seiichi Takeda, Research and Development Center, Fuso Pharmaceutical Industries LTD., 2-3-30, Morinomiya, Joto-ku, Osaka 536-8523, Japan. Tel: +81 669693131, Fax: +81 669642706, e-mail: sei-takeda@fuso-pharm.co.jp

Key Words: Medium molecular weight heparinyl phenylalanine (MHF), extracellular superoxide dismutase (EC-SOD), mouse, radical scavenge, free radical. scavengers is unknown. In this study, we examined the change in the plasma extracellular superoxide dismutase (EC-SOD) activity after intravenous administration of MHF and MHL to clarify how MHF and MHL function as radical scavengers.

\section{Materials and Methods}

Animals. Specific pathogen-free male ICR mice (4 weeks old) were purchased from Japanese Charles River Ltd., (Yokohama, Japan) and used for the experiment after a one-week acclimation. The mice were maintained at $23 \pm 2^{\circ} \mathrm{C}$ (room temperature) and $50 \pm 5 \%$ (relative humidity) under an artificial 12-hour light-dark cycle (7:00 on 19:00 off). Food and water were given ad libitum during the experimental period. All procedures followed the office regulations for the Care and Use of laboratory animals approved by the animal experimentation committee of Fuso Pharmaceutical Industries Ltd., Japan (approval number: PDS9702).

Materials. MHF and MHL (mean molecular weight: 8,500-10,000), synthesized at Fuso Pharmaceutical Industries Ltd. Research and Development Center (Osaka, Japan), and bulk HE (Scientific Protein Laboratories, Waunakee, WI, USA) were used (3).

Effects of HE, MHF and MHL on the plasma EC-SOD activity in mice. HE, MHF or MHL was injected into the tail vein of mice at several doses $(2.5,5.0,10.0,20.0$ and $40.0 \mathrm{mg} / \mathrm{kg} / 10 \mathrm{ml})$. Twenty minutes later, $0.5 \mathrm{ml}$ of blood was collected from the abdominal aorta using the heparinized injection cylinder. To avoid leakage of SOD from red blood cells by hemolysis, collected blood was kept in a test tube containing $2 \mathrm{ml}$ of $0.25 \mathrm{M}$ sucrose (including $\mathrm{HE} 10 \mathrm{U} / \mathrm{ml}$ ) and cooled in ice until analysis (as a sample). Twenty $\mu \mathrm{l}$ of the sample, $2 \mathrm{ml}$ of $0.25 \mathrm{M}$ sucrose and $10 \mathrm{ml}$ of saline were put in a test tube and mixed gently. The mixture was then centrifuged $\left(1,000 \times g, 10 \mathrm{~min}, 4^{\circ} \mathrm{C}\right)$ and the upper layer removed. The EC-SOD activity in the upper layer was measured according to the method of Oyanagui and Sato (4). Data were indicated using nitrite units ( $\mathrm{NU} / \mathrm{ml}$ plasma) of SOD.

Statistical analysis. Data are represented as the means \pm standard error (S. E.) and significance was evaluated by analysis of variance (ANOVA) followed by the Spjotvoll and Stoline-test (corrected Tukey method) because the number of samples among the groups was different. The differences were assessed at a significance level of 0.05 . 


\section{Results}

Effects of HE, MHF and MHL on the plasma EC-SOD activity in mice. When HE was administered into mice intravenously, the plasma EC-SOD activity increased significantly with doses of $2.5 \mathrm{mg} / \mathrm{kg} / 10 \mathrm{ml}$ or higher. The increase in the plasma EC-SOD activity peaked at a dose of $10.0 \mathrm{mg} / \mathrm{kg} / 10 \mathrm{ml}$. The plasma EC-SOD activity of the $10.0 \mathrm{mg} / \mathrm{kg} / 10 \mathrm{ml}$-administered group increased by approximately 4-times compared with the PBS-administered control group. Furthermore, HE, higher than $10.0 \mathrm{mg} / \mathrm{kg} / 10 \mathrm{ml}$, did not show any significant increase in the plasma EC-SOD activity compared with the PBS-administered control group. In the groups administered MHF and MHL, the plasma EC-SOD activity increased from the doses of 2.5 to $5.0 \mathrm{mg} / \mathrm{kg} / 10 \mathrm{ml}$. The peak values of the plasma EC-SOD activity of the groups administered MHF and MHL were approximately 5-times in the case of MHF and 4-times in the case of MHL compared with the control group. The dose of MHF and MHL-EC-SOD activity curve formed a bell-shape, similar to HE (Figure 1).

Changes in the plasma EC-SOD activity after $\mathrm{HE}, \mathrm{MHF}$ and $M H L$ were administered to the mice until $120 \mathrm{~min}$. The plasma EC-SOD activities of mice peaked at $5 \mathrm{~min}$ after administration of $\mathrm{HE}, \mathrm{MHF}$ and MHL $(10 \mathrm{mg} / \mathrm{kg} / 10 \mathrm{ml})$. At 5 min after the injection, the plasma EC-SOD activities of mice decreased until $120 \mathrm{~min}$ in the groups administered MHF and MHL. However, the plasma EC-SOD activities of mice administered HE did not change after 20 min (Figure 2).

\section{Discussion}

Many researchers have already reported that plasma ECSOD activity is increased by administration of $\mathrm{HE}$ in mammals, such as humans, porcine, bovine, canines, cats and mice (4-10). In this paper, we chose the mouse as an experimental animal to investigate the effects of $\mathrm{HE}, \mathrm{MHF}$ and MHL on SOD activity in vivo. In general, Unit of SOD (Unit/ml) is obtained by the cytochrome $c$ method of McCord and Fridovich (11). However, the cytochrome $c$ method can only be applied to samples that have a strong radical scavenge ability. Furthermore, the procedure is very complex and a highly sensitive spectrophotometer is needed. In this experiment, we utilized Oyanagui and Sato's method (4). Their method is not complex, shows good color development and the necessary reagents are economical. In addition, the absorbance changes can be detected by a conventional spectrophotometer. Moreover, the sensitivity of this method is more than 3-times higher than the cytochrome $c$ method (12).

First, the effects of several doses of HE, MHF or MHL on mouse plasma EC-SOD activity were investigated. The increase in the plasma EC-SOD activities of mice were confirmed after intravenous administration of $\mathrm{HE}$, MHF or MHL. The dose-EC-SOD activity curves formed a bell-shape. In the case of HE, the plasma EC-SOD activity increased significantly at doses of $2.5 \mathrm{mg} / \mathrm{kg} / 10 \mathrm{ml}$ or higher with a prolonged APTT. On the other hand, the plasma EC-SOD activity increased from doses of 2.5 to $5.0 \mathrm{mg} / \mathrm{kg} / 10 \mathrm{ml}$ without any prolonged APTT in groups administered MHF and MHL (APTT was measured after HE, MHF and MHL were administered to mice as in reference (2)).

EC-SOD in the blood circulation forms a tetramer and has four HE-binding sites (4). This tetramer without any bound $\mathrm{HE}$ is the inactive form. However, EC-SOD is activated by binding of two HE to two binding sites and EC-SOD can connect with other EC-SODs using the empty binding sites. That is, a proper dose of HE activates EC-SOD, while an excess dose of HE cannot activate EC-SOD (4). We speculate that MHF and MHL may also function as HE as the dose-EC-SOD activity curves formed a bell-shape.

Barzu et al. studied the binding of HE and low molecular weight heparin fragments (CY 222; molecular weight range: $1,500-8,000)$ to human vascular endothelial cells. As a result, HE indicated a much higher affinity to the vascular endothelium than CY 222 and a fraction of bound HE was reported to be internalized by the vascular endothelium (13). According to their paper, HE may bind to the vascular endothelium with a high affinity and a fraction of bound HE is internalized by the vascular endothelium, while smaller amounts of MHF and MHL bind to the vascular endothelial cells. We surmise that this is the reason why MHF and MHL exhibited a higher ability than HE to activate EC-SOD after intravenous injection.

Second, we investigated the changes in the plasma ECSOD activity after HE, MHF and MHL (10 mg/kg/10 ml) were administered to the mice until $120 \mathrm{~min}$. The plasma EC-SOD activity of the mice peaked at $5 \mathrm{~min}$ after the administration and decreased gradually until $120 \mathrm{~min}$. HE demonstrated a smaller degree of decrease in EC-SOD activity than MHF and MHL that did not change after 20 min. We speculate that MHF and MHL were broken-down more quickly than $\mathrm{HE}$ as the molecular weights of MHF and MHL are smaller than HE's. However, MHF possessed a higher ability than HE to increase EC-SOD activity until $60 \mathrm{~min}$. Considering the reduced side-effects of MHF, this result suggests that $\mathrm{MHF}$ is superior to $\mathrm{HE}$ as a candidate for clinical use.

Recently, participation of free radicals is reported in several diseases, such as in the cardiovascular system (14), Alzheimer's disease (15), arteriosclerosis (16), myocardial infarction (17), cerebral infarction (18), Parkinson's disease (19), pancreatitis (20), glomerulonephritis (21), diabetes (22), cirrhosis (23), stomach ulcers (24), atopic dermatitis (25) and asthma $(26,27)$. Although the research on EC-SOD is advanced and several radical scavengers are under 


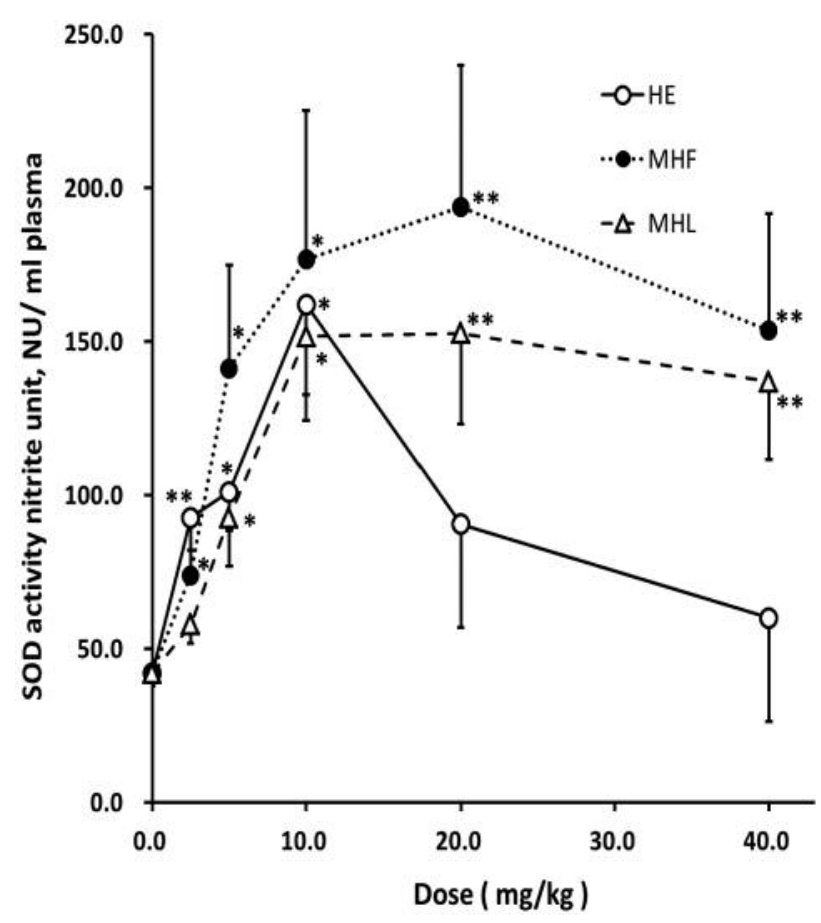

Figure 1. Increase in the plasma extracellular superoxide dismutase (EC-SOD) activity of mice injected by several doses of heparin (HE), medium molecular weight heparinyl phenylalanine (MHF) and medium molecular weight heparinyl leucine (MHL) at 20 min after the injection. Each point represents the mean $\pm S$. E. of 8 or 11 animals. $* * p<0.01$, ${ }^{*} p<0.05$ vs. PBS (by Spjotvoll and Stoline-test).

development, the number of ethical drugs is few. MHF may be a promising candidate for a radical scavenger to increase EC-SOD activity with a low risk of hemorrhage.

\section{Conflicts of Interest}

The Authors declare no conflict of interest associated with this manuscript.

\section{References}

1 Takeda S, Toda T and Nakamura K: Middle molecular weight heparinyl amino acid derivatives (MHADs) function as indirect radical scavengers in vitro. Pharmacol Pharmacy 7: 117-123, 2016.

2 Takeda S, Toda $\mathrm{T}$ and Nakamura K: Inhibitory Effects of Medium Molecular Weight Heparinyl Amino Acid Derivatives on Ischemic Paw Edema in Mice. In Vivo 30: 433-437, 2016.

3 Araki $\mathrm{H}$, Nishikawa $\mathrm{H}$, Tanaka S, Nakamura K, Ohtani H, Nishimura S, Shimada C, Takeda S, Kawai K, Kitagawa C, Kuwahara M and Abe T: Japan Patent Kokai: 1997-286803, 1997.

4 Oyanagui Y and Sato S: Heparin, a potent releasing agent of extracellular superoxide dismutase (EC-SOD C), suppresses ischaemic paw oedema in mice. Free Radic Res Commun 9: 8799, 1990.

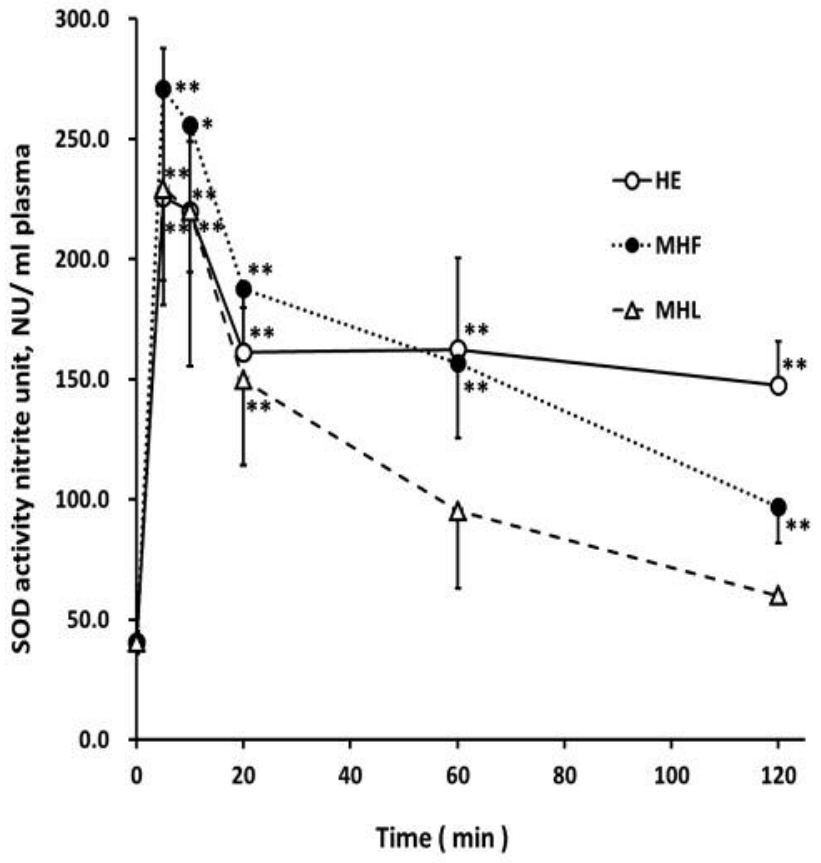

Figure 2. Time course of plasma extracellular superoxide dismutase $(E C-S O D)$ activities of mice after the injection of heparin $(H E)$, medium molecular weight heparinyl phenylalanine $(\mathrm{MHF})$ and medium molecular weight heparinyl leucine $(\mathrm{MHL})(10 \mathrm{mg} / \mathrm{kg} / 10 \mathrm{ml})$. Each point represents the mean $\pm S$. E. of 8 or 10 animals. $* *<<0.01, * p<0.05$ vs. PBS (by Spjotvoll and Stoline-test).

5 Karlsson K and Marklund SL: Heparin-induced release of extracellular superoxide dismutase to human blood plasma. Biochem J 242: 55-59, 1987.

6 Karlsson K and Marklund SL: Extracellular superoxide dismutase in the vascular system of mammals. Biochem J 255: 223-228, 1988.

7 Adachi T, Yamada H, Futenma A, Kato K and Hirano K: Heparin-induced release of extracellular superoxide dismutase from (V) to plasma. J Biochem 117: 586-590, 1995.

8 Becker M, Menger MD and Lehr HA: Heparin-released superoxide dismutase inhibits postischemic leukocyte adhesion to venular endothelium. Am J Physiol 267: H925-H930, 1994.

9 Hiebert LM and Liu JM: Heparin protects cultured arterial endothelial cells from damage by toxic oxygen metabolites. Atherosclerosis 83: 47-51, 1990.

10 Oyanagui Y and Sato S: Suppression of carrageenan paw oedema in rats and mice by heparin-induced EC-SODs. Free Radic Res Commun 12: 229-237, 1991.

11 McCord J M and Fridovich I: Superoxide dismutase. An enzymic function for erythrocuprein (hemocuprein). J Biol Chem 244: 6049-6055, 1969.

12 Oyanagui Y: Reevaluation of assay methods and establishment of kit for superoxide dismutase activity. Anal Biochem 142: 290296, 1984.

13 Barzu T, Molho P, Tobelem G, Petitou M and Caen J: Binding and endocytosis of heparin by human endothelial cell in culture. Biochim Biophys Acta 845: 196-203, 1985. 
14 Lüscher TF: Ageing, inflammation, and oxidative stress: final common pathways of cardiovascular disease. Eur Heart J 36: 3381-3383, 2015

15 Prasad KN: Simultaneous activation of Nrf2 and elevation of antioxidant compounds for reducing oxidative stress and chronic inflammation in human Alzheimer's disease. Mech Ageing Dev 153: 41-47, 2016.

16 Perrotta I and Aquila S: The role of oxidative stress and autophagy in atherosclerosis. Oxid Med Cell Longev 2015: $130315,2015$.

17 Sun SJ, Wu XP, Song HL and Li GQ: Baicalin ameliorates isoproterenol-induced acute myocardial infarction through iNOS, inflammation, oxidative stress and P38MAPK pathway in rat. Int J Clin Exp Med 8: 22063-22072, 2015.

18 Zhang XH, Lei H, Liu AJ, Zou YX, Shen FM and Su DF: Increased oxidative stress is responsible for severer cerebral infarction in stroke-prone spontaneously hypertensive rats. CNS Neurosci Ther 17: 590-598, 2011.

19 Medeiros MS, Schumacher-Schuh A, Cardoso AM, Bochi GV, Baldissarelli J, Kegler A, Santana D, Chaves CM, Schetinger MR, Moresco RN, Rieder CR and Fighera MR: Iron and oxidative stress in Parkinson's disease. An observational study of injury biomarkers. PLoS One 11: e0146129, 2016.

20 Rustagi T and Njei B: Antioxidant therapy for pain reduction in patients with chronic pancreatitis: a systematic review and metaanalysis. Pancreas 44: 812-818, 2015.

21 Kinoshita Y, Kondo S, Urushihara M, Suga K, Matsuura S, Takamatsu M, Shimizu M, Nishiyama A, Kawachi $H$ and Kagami S: Angiotensin II type I receptor blockade suppresses glomerular renin-angiotensin system activation, oxidative stress, and progressive glomerular injury in rat anti-glomerular basement membrane glomerulonephritis. Transl Res 158: 235248,2011
22 Saad MI, Abdelkhalek TM, Saleh MM, Kamel MA, Youssef M, Tawfik $\mathrm{SH}$ and Dominguez H: Insights into the molecular mechanisms of diabetes-induced endothelial dysfunction: Focus on oxidative stress and endothelial progenitor cells. Endocrine 50: 537-567, 2015.

23 Iwasa M, Kobayashi Y, Mifuji-Moroka R, Hara N, Miyachi H, Sugimoto R, Tanaka H, Fujita N, Gabazza EC and Takei Y: Branched-chain amino acid supplementation reduces oxidative stress and prolongs survival in rats with advanced liver cirrhosis. PLoS One 8: e70309, 2013.

24 Singh LP, Mishra A, Saha D and Swarnakar S: Doxycycline blocks gastric ulcer by regulating matrix metalloproteinase-2 activity and oxidative stress. World J Gastroenterol 17: 33103321, 2011

25 Plevnik Kapun A, Salobir J, Levart A, Tavčar Kalcher G, Nemec Svete A and Kotnik T: Vitamin E supplementation in canine atopic dermatitis: improvement of clinical signs and effects on oxidative stress markers. Vet Rec 175: 560, 2014.

26 Kacprzak D and Pawliczak R: Does aspirin-induced oxidative stress cause asthma exacerbation? Arch Med Sci 11: 494-504, 2015.

27 Al-Harbi NO, Nadeem A, Al-Harbi MM, Imam F, Al-Shabanah OA, Ahmad SF, Sayed-Ahmed MM and Bahashwan SA: Oxidative airway inflammation leads to systemic and vascular oxidative stress in a murine model of allergic asthma. Int Immunopharmacol 26: 237-245, 2015. 